\title{
СОХРАНЕНИЕ СНЕЖНО-ЛЕДЯНЫХ ОБРАЗОВАНИЙ В КУНГУРСКОЙ ЛЕДЯНОЙ ПЕЩЕРЕ В ПЕРИОДЫ ПОТЕПЛЕНИЯ (НА ПРИМЕРЕ 2020 Г.)
}

\author{
А.С. Казанцева, А.В. Красиков \\ Горный институт УрО РАН, г. Пермь
}

\begin{abstract}
Аннотация: Гляциологический мониторинг - комплекс мероприятий, направленных на исследование состояния ледяного убранства в Кунгурской Ледяной пещере. В течение года в зависимости от климатических и микроклиматических факторов мощность льда меняется, баланс массы льда изменяется с отрицательного на положительный и наоборот. Для регулирования и сохранения снежно-ледяных образований существует и действует регламент проветривания, меры которого совместно с мероприятиями по кольматации трещин гротов снегом, укладке ледяных глыб вдоль тропы в зоне отрицательной температурной аномалии позволили минимизировать потери снежно-ледяных образований в 2020 г. По сравнению с пещерами южноевропейских стран потери льда в Кунгурской ледяной пещере оказались минимальными, хотя температура воздуха как на поверхности, так и внутри пещеры, была максимальной за последние три года.
\end{abstract}

Ключевые слова: Кунгурская Ледяная пещера, снежно-ледяные образования, период потепления.

\section{Введение}

Снежно-ледяные образования являются основной достопримечательностью Кунгурской Ледяной пещеры (КЛП). Таяние и ежегодное восстановление ледяных образований - естественный процесс в пещере. С момента освоения и благоустройства пещеры мощность оледенения стала зависеть от естественных, технических и антропогенных условий: изменения температуры наружного воздуха, ежегодного подъема как подземных, так и поверхностных вод (р. Сылвы), сооружения входного и выходного тоннелей, искусственного проветривания и количества экскурсантов.

Начиная с 1948 г. в КЛП проводится постоянный мониторинг за состоянием оледенения. Гляциологическим наблюдением и восстановлением ледяных образований начал заниматься В.С. Лукин, а после 1969 г. продолжил Е.П. Дорофеев, который дал наиболее полное описание всех видов льда в пещере. За время наблюдений были установлены причины возникновения и условия сохранения оледенения в зоне отрицательной температурной аномалии [1,2].

В рамках гляциологического мониторинга требуется формирование оптимальных факторов для возобновления, сохранения и роста ледяных образований и условий, обеспечивающих наибольшую продолжительность их существования. Одним из важных мероприятий является создание возможности накопления в пещере достаточного количества зимнего холода. Постоянные ежемесячные замеры льда в течение года позволяют выявить колебания объемов льда по всем реперам за весь период мониторинга, а также общие тенденции изменений.

Данная статья посвящена анализу изменения оледенения в КЛП в периоды общего потепления, когда наблюдаются повышенные температуры как в теплый, так и в холодный периоды. Таким оказался 2020 г. В 2020 г. за последние три года зафиксирована максимальная среднегодовая температура воздуха на поверхности $\left(+4,3^{\circ} \mathrm{C}\right)$, при этом в пещере в зоне постоянных отрицательных и переходных температур также произошло изменение температуры, что не могло не сказаться на развитии снежно-ледяных образований.

\section{Методы исследования}

В рамках гляциологического мониторинга замеры льда осуществлялись по 16 реперам, установленным в многолетних наледях в зоне постоянного оледенения. В периоды максимального и минимального оледенения проводились наблюдения за ледяными об- 
разованиями, которые включают в себя полное описание и фотофиксацию всех ледяных форм, имеющихся в Кунгурской Ледяной пещере на данный период. Измерения температуры воздуха в пещере выполнялись с использованием термометров марки ТЛ-4 (цена деления $0,1^{\circ} \mathrm{C}, 0,2^{\circ} \mathrm{C}$ ) и логгеров HOBO Water Temp Pro v2, на поверхности метеостанции «MeteoscanPro 923».

\section{Результаты исследования}

Как упоминалось ранее, важным аспектом образования и сохранения снежно-ледяных образований в пещере является накопление холода в период с ноября по март. Для этого существует и действует регламент проветривания, согласно которому происходит контроль за своевременным открытием и закрытием входных и шлюзовых дверей, системы вентиляционного канала и скважины, пробуренной в гроте Центральный при определенной температуре. Нами проанализированы температурные изменения и соотношения прихода и расхода массы ледяных отложений в пещере за теплый и холодный период года (баланс массы льда) в гротах с отрицательными и переходными температурами в границах зоны постоянного оледенения (гроты Бриллиантовый, Первый (Старый вход), Полярный, Данте, Крестовый и переход Горе Толстякам и Высоким) в 2020 г.

Данные по температуре в гротах со снежно-ледяными образованиями сопоставлены с данными изменения температуры воздуха на поверхности (рис. 1). На поверхности в 2020 г. по сравнению с 2018-2019 гг. зафиксированы наивысшие значения температуры воздуха, что, соответственно, привело к повышению температуры воздуха в гротах КЛП. В этот период в пещере также отмечены максимальные температуры за последние три года (рис. 1a). Максимальные значения как на поверхности, так и в пещере, наблюдаются в летнее время (июль-август рис. 1б).

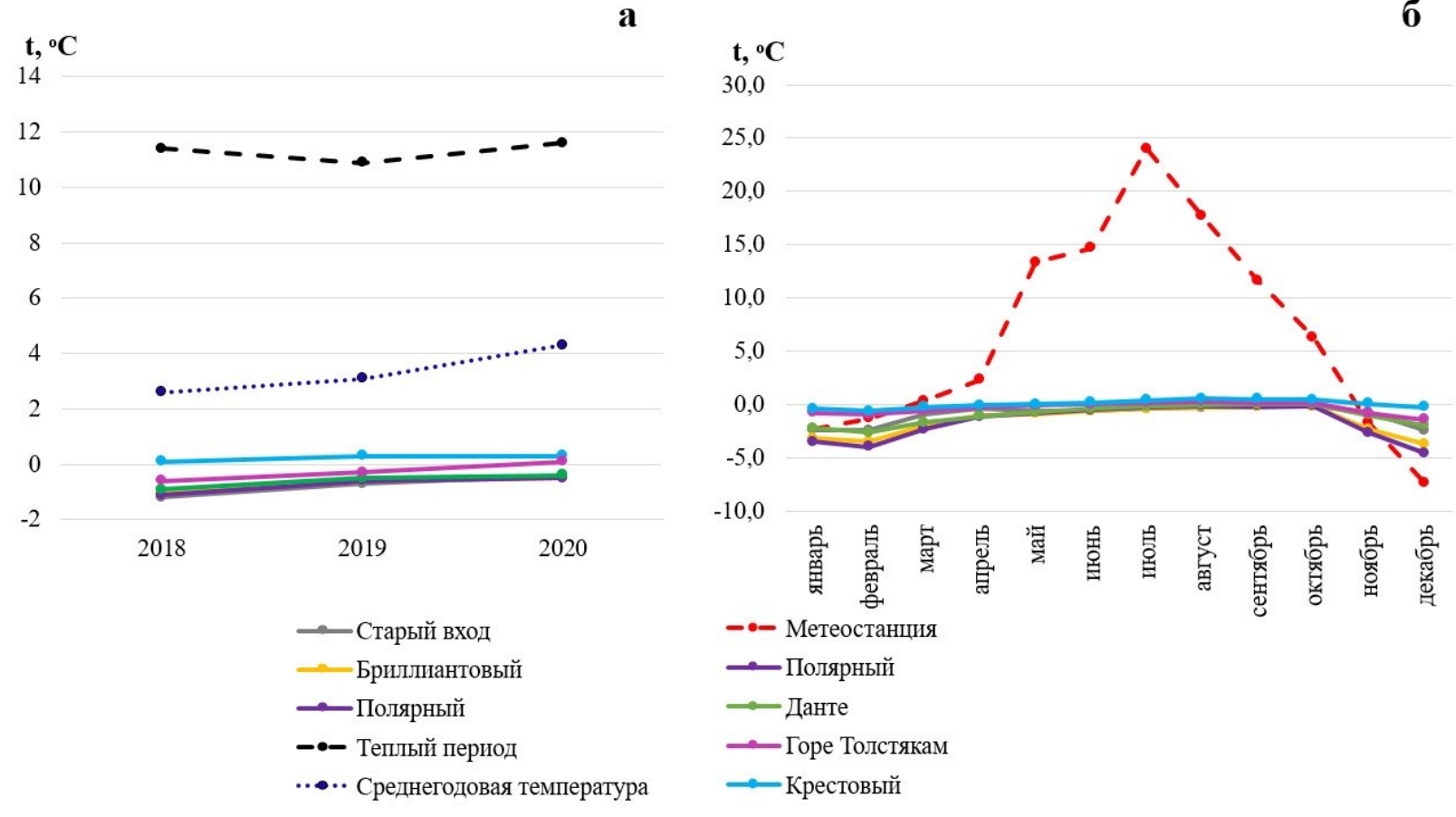

Рис. 1. Динамика температуры на поверхности и в гротах со снежно-ледяными образованиями: а - за три года; б - в 2020 г.

Непрерывные замеры льда по реперам и расчет баланса массы льда показывают, что накопление массы льда происходит во входной части пещеры: гроты Бриллиантовый и Первый (Старый вход) со значениями прироста от 0 до 2 мм/год (рис. 2). Также положительный прирост наблюдается в гроте Крестовый (возле термометра и наледь в гроте 
«Отшельник»). В этих гротах аккумуляция (накопление) льда превышает абляцию (потерю). Рост льда в этих галереях составляет от 14 до 21 мм/год. Повышение температуры на поверхности и в гротах пещеры не привели к потере льда в привходовой части в теплый 2020 г. Произошел прирост массы льда и, следовательно, незначительно увеличился объем наледей.

В переходах между гротами Бриллиантовый-Полярный, Полярный-Данте, между Большим и Малым Крестовым, проходе Горе Толстякам и Высоким и гроте Данте баланс массы льда отрицательный со значениями от -2 до -48 мм/год (рис. 2). Здесь абляция превышала аккумуляцию. Наибольшая потеря льда зафиксирована по реперу, расположенному между гротами Большой и Малый Крестовый. Потеря мощности происходила в основном в зимний период за счет испарения льда при поступлении холодного воздуха в пещеру. В летний период потеря льда за счет его таяния была минимальной.

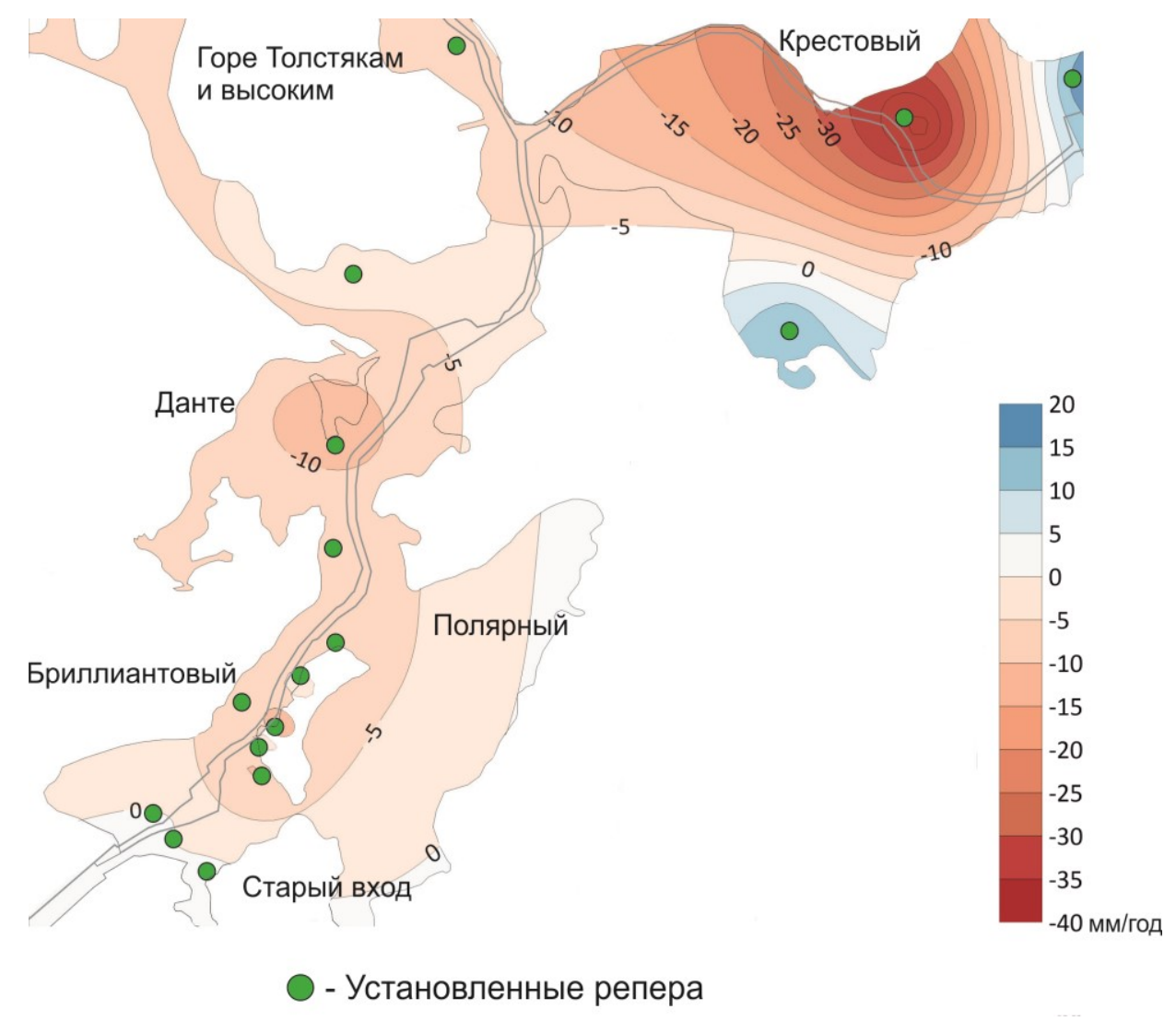

Рис. 2. Баланс массы льда в гротах КЛП за 2020 г.

В 2020 г. площадь сезонного оледенения уменьшилась по сравнению с аналогичным периодом прошлого года, но при этом границы максимального оледенения остаются постоянными на протяжении трех последних лет: от входного тоннеля до входной части грота Руины (в пределах Большого экскурсионного маршрута) и от прохода Горе Толстякам и Высоким до входа в грот Геологов и Смелых (в пределах Малого экскурсионного маршрута; рис. 3). Остальная часть пещеры находится в пределах влияния зоны постоянных положительных температур, где льда нет.

Кунгурская Ледяная пещера в теплый 2020 г. потеряла значительно меньше льда по сравнению с южноевропейскими пещерами Scărișoara Ice Cave, Chionotrypa Cave, Crna Ledenica, Ledena jama v Paradani [3]. Здесь потери льда в теплый 2019 г. составили по- 
рядка 150-1000 м³, мощность льда снизилась от 0,3 м до 2,0 м. 2019 год был исключительно влажным в Южной Европе: поздняя весна и лето 2019 г. обусловили быстрое таяние пещерного льда. Выпадение дождей в этот период привело к большой потере массы льда в пещерах, а также на поверхностных ледниках.

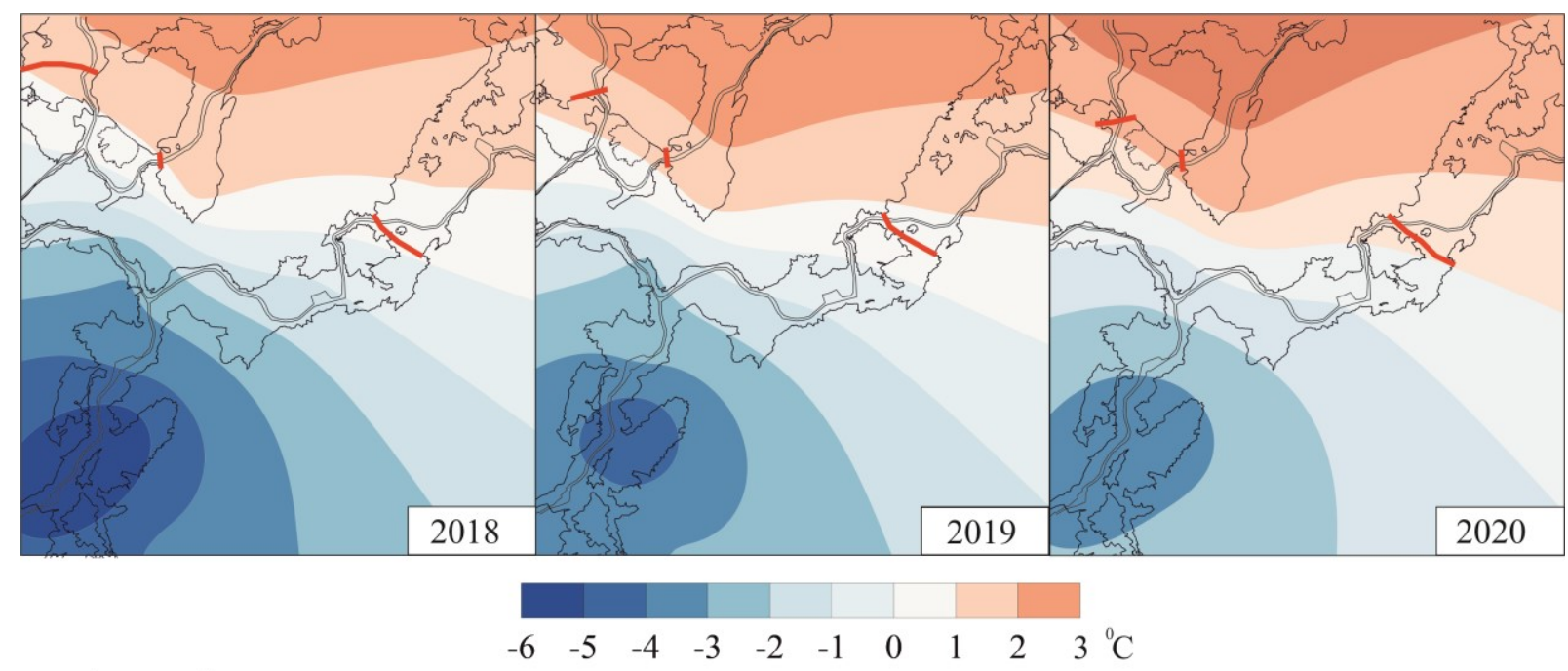

Граница максимального оледенения

Рис. 3. Границы максимального оледенения за 2018-2020 гг. в соотношении с изменением температуры в гротах

Мероприятия, к которым можно отнести кольматацию трещин снегом, укладку ледяных глыб вдоль тропы в зоне отрицательной температурной аномалии, соблюдение режимов проветривания по открытию и закрытию вентиляционного канала в гроте Бриллиантовый, дверей входного и выходного тоннелей и Старого входа, позволили в 2020 г. минимизировать потери объемов многолетних льдов в пещере, хотя зимний и летний периоды 2020 г. были значительно теплее аналогичных периодов 2018-2019 гг.

\section{Выводы}

Несмотря на изменение климатических и микроклиматических параметров в сторону увеличения температуры, в Кунгурской Ледяной пещере в 2020 г. ежегодные мероприятия по регулированию поступления потока воздуха с поверхности позволили минимизировать потери снежно-ледяных образований.

Это еще раз подтверждает, что гляциологический мониторинг позволяет получить оперативную информацию по состоянию и динамике развития снежно-ледяных образований, а соблюдение режимов проветривания согласно регламенту дает возможность выработать меры по восстановлению и сохранению снежно-ледяного убранства КЛП.

\section{БИБЛИОГРАФИЧЕСКИЙ СПИСОК}

1. Красиков А.В., Казанцева А.С., Богомаз М.В. Многопрофильный мониторинг в Кунгурской Ледяной пещере // Горн. журн. - 2018. - № 6. - С. 60-64.

2. Кунгурская ледяная пещера: опыт режимных наблюдений / ГИ УрО РАН; под ред. В.Н. Дублянского; [отв. ред. А.И. Кудряшов]. - Екатеринбург, 2005. - 376 с.: ил.

3. Persoiu A., Buzjak N., Onaca A., Pennos C., Sotiriadis Y., Ionita M., Zachariadis S., Styllas M., Kosutnik J., Hegyi A., Butorac V. Unprecedented loss of surface and cave ice in SE Europe related to record summer rains in 2019 // The Cryosphere Discussions. [preprint]. - 2020. - https://doi.org/10.5194/tc-2020-287. 